\title{
THE ANALYSIS FORMULATION OF THE LOWEST ASTRONOMICAL TIDE (LAT) BASED ON THE TIME OBSERVATION (THE CASE STUDY OF BENOA WATERS)
}

\author{
Okol Sri Suharyo, Johar Setiadi, Nawanto Budi Sukoco, Kuncoro \\ Indonesia Naval Technology College, STTAL, Surabaya Indonesia
}

\begin{abstract}
According to the definition of International Hydrographic Organization (IHO) M-13 2005, the Lowest Astronomical Tide (LAT) is Internationally used as chart datum, which is used as instruction for measuring the validation of high water surface in the Hydro-oceanography survey. It is predicted by tide prediction for 18.61 years. This research is observed minimized in one year. In determining of LAT, it will be analyzed by the tide Constanta and prediction analysis. The analysis of tide Constanta will be calculated by the Rayleigh numbering method (the smallest quadrat), start on tide data observation for one month, two months, three months, four months, six months until twelve months data of tide observation. Afterward, from that analysis results of tide Constanta, it can be predicted the tide for 18.61 years. From this result, the prediction will be found the difference of the LAT value of tide data less than in one year with tide data in one year. Then, from the difference of $L A T$ values can be analyzed at a significant level by using the statistical approach. From the result of the LAT calculation by using data observation of tide in one year will be got the LAT position that is $43.3 \mathrm{~cm}$. If comparing with LAT value which uses a variety of data less than in one year, it will result in the level of significant differences. In this case, LAT value thas is calculated by data less than in one year cannot be equated with LAT which is used by observation of tide data in one year.
\end{abstract}

Keywords: LAT, Tide Component, and interval of tide observation.

\section{INTRODUCTION}

Knowledge of tidal conditions in the waters of Indonesia with a coastline of around $81,000 \mathrm{~km}$ is very important for Indonesia because this knowledge can be used to monitor tsunami warnings, hydrographic surveys, mapping, defense, navigation, and sports in marine waters. One knowledge of tidal conditions that play an important role in navigation is the knowledge of the lowest astronomical retrograde or Lowest Astronomical Tide (LAT). The availability of tidal data belonging to the Information and Geospatial Agency (BIG) from the measurement results at the tidal waters of the Benoa waters is a supportive modality in analyzing LAT at that location. The data used in this study is tidal observation data in Benoa waters for 1 year.

LAT is the lowest sea level position that occurs under average meteorological conditions and is the result of a combination of astronomical influences (IHO, 1993). The definition of average meteorological conditions is related to meteorological influences on the position of the sea surface under normal conditions, not meteorological conditions that can cause the sea level to fall or rise in extreme ways. For example, such as during a rainstorm, which can cause a sea level position that is lower than the LAT or during a tsunami that can cause a higher sea level position than the highest possible astronomical tide.In this study, the authors will analyze the difference in LAT values from tidal observation data with a range of observations ranging from data one month, two months, three months, four months, six months to tidal observation data for 12 months. After obtaining the monthly variation LAT value, it will be compared with the LAT value using one-year data and can be seen the level of difference in the LAT value.

Based on the background of the problem described earlier, the problem can be formulated in the preparation of this final assignment to determine how much the level of difference in LAT values obtained from the results of tidal predictions with observations of one month, two months, three 
months, four months, six month and observation data for 12 months. This study aims to determine the difference in the value of LAT calculated by the observation interval of one month, two months, three months, four months, six months and 12 months. Furthermore, from the difference in the LAT value, a significance level analysis will be carried out using the statistical approach method.

Tidal observation data from the Information \& Geospatial Agency (BIG) in Benoa waters for 1 year. Observations using ATT chart type tools Kempten with tide station are at $08^{\circ} 46$ ' 00 " $\mathrm{U}$ and $115^{\circ} 13^{\prime} 00^{\prime \prime} \mathrm{T}$. The limitations of the problems in this assessment include:

a. The tide data used for the purposes of this study are assumed to be free from systematic errors and major errors.

b. Tidal analysis calculations will use Matlab 7.0.1 software with the T-Tide Program with the Least Square method to determine tidal harmonic constants and tide predictions in determining LAT values.

This study aims to determine the difference in the value of LAT calculated by the observation interval of one month, two months, three months, four months, six months and 12 months. Furthermore, from the difference in the LAT value, a significance level analysis will be carried out using the statistical approach method.

Research on the analysis of determining Astronomical Tide Lowest has been done by many previous authors including the following:

a. Cecep Kurniawan, (2012) with the title Application of Lowest Astronomical Tide (LAT) Approach in Determining Base Points, Case Study of Tanjung Datu, West Kalimantan.

b. Gading Putra Hasibuan, (2009) with the title of Lowest Astronomical Lowdown Analysis in Sabang, Sibolga, Padang, Cilacap and Benoa Waters using Superposition of Tidal Harmonic Components.

\section{MATERIAL AND METHODS}

\subsection{The Tidal}

Tides (tides) of the sea is a phenomenon of periodic rise and fall of sea levels caused by tidal forces that arise due to the attraction of celestial bodies, especially the moon and sun (Rawi, 1985).

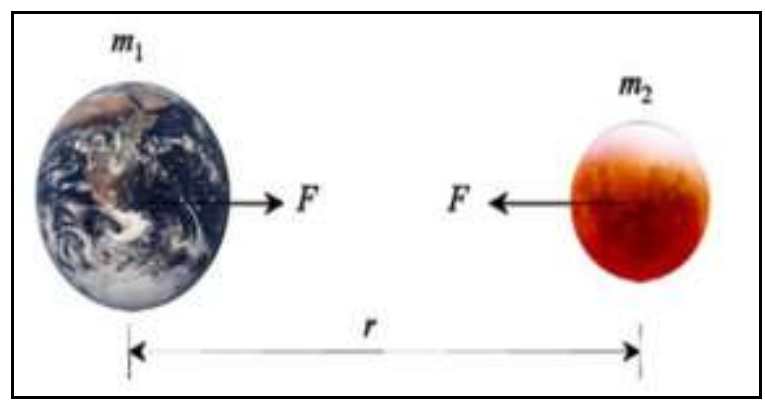

Fig.1 Earth and Moon Attractiveness.

The tidal power plant is explained by the theory of universal gravity which states that objects with masses of $\mathrm{m} 1$ and $\mathrm{m} 2$ will have an attractive force of $F$ whose magnitude is proportional to the mass multiplication and is proportional to the square of the distance. (Poerbondono and Eka Djunarsyah, 2005).

The tidal movement has a period of 12 hours 25 minutes on a dual daily tide type and 24 hours 50 minutes on a single daily tidal type, this movement is also accompanied by a horizontal movement of seawater mass called tidal current. The period during which sea level rises associated with tidal events is called rising water and sea level is at the highest position called high water. Conversely, the period during which the sea level falls is called down water and the sea level at the lowest position is called low water. The high difference between low water and high water that follows is called water riding, the amount of which is not fixed. Sketching the tidal wave in the form of a curve line is shown in Figure 2. 


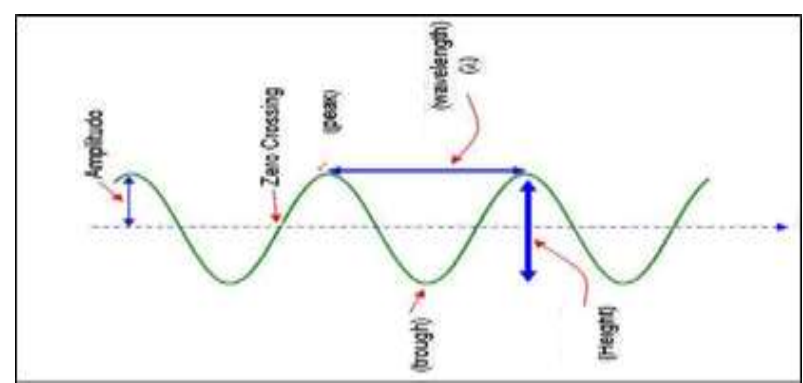

Fig.2 Sketch of tidal waves

The movement of up and down sea levels takes place periodically, this is caused by the periodic circulation of the earth, moon, and sun, which is shown in Figure 2. The attraction of the moon and the sun as a tidal driving force while working simultaneously and when others work opposite each other. The position of the earth, moon, and sun in one line occurs twice for 29.5 days.

At the time of the new moon, the position of the moon is right between the sun and the earth, whereas when the moon is full, the earth is between the moon and the sun. These conditions produce maximum tidal driving forces which give rise to large tides in places on the surface of the earth that are one line with the position of the moon and sun. The position of the sun, moon, and earth at the full moon and the bandage can be shown in Figure 3.

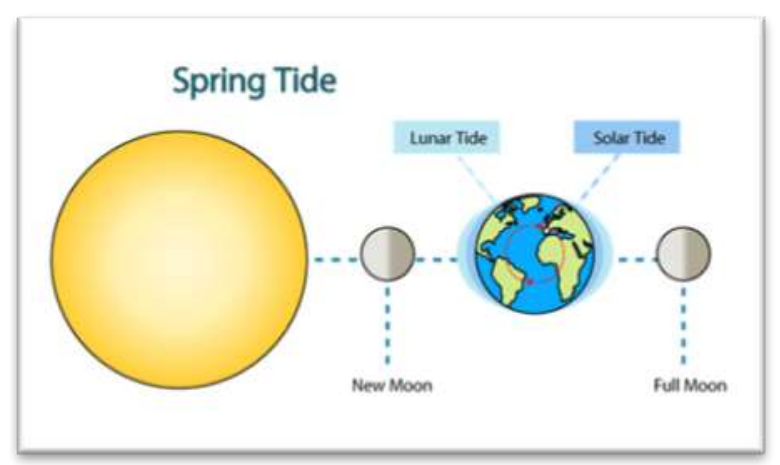

Fig.3 Circulation of the earth, moon, and sun

\subsection{Tidel Type}

Based on the tidal curves obtained in various places, we can know the differences in time, water, and tide types caused by various local factors such as sea depth, water area, land mass, seabed topography, strait width, bay shape, and so on, so that in various places different tides occur. The tidal base character is indicated by the type of tide.

The tidal type of water can be determined using the Formal formula, which is the ratio of the number of the main constant amplitude of a single daily tide to the number of the main constant amplitude of the double daily tide.

Based on the $F$ value, the tides are grouped according to the types shown in Table 1

Table 1. Types of tides based on the value of $F$

\begin{tabular}{|c|c|l|}
\hline F Value & Tide Type & \multicolumn{1}{|c|}{ Phenomena } \\
\hline $0<\mathrm{F} \leq 0.25$ & Diurnal Tide & $\begin{array}{l}2 \text { times a day and } \\
\text { overnight pairs with } \\
\text { relatively the same } \\
\text { height }\end{array}$ \\
\hline $0.25<\mathrm{F} \leq 1.5$ & $\begin{array}{c}\text { Mixed } \\
\text { Semidiurnal } \\
\text { Tide } \\
\text { overnight a day } \\
\text { different height and } \\
\text { different intervals }\end{array}$ \\
\hline $1.5<\mathrm{F} \leq 3$ & $\begin{array}{c}\text { Mixed } \\
\text { Diurnal Tide }\end{array}$ & $\begin{array}{l}1 \text { time or 2 pairs a } \\
\text { night with } \\
\text { different intervals }\end{array}$ \\
\hline $\mathrm{F}>3$ & $\begin{array}{c}\text { Semi-Diurnal } \\
\text { Tide }\end{array}$ & $\begin{array}{l}1 \text { pair a day and } \\
\text { overnight }\end{array}$ \\
\hline
\end{tabular}

\subsection{Tidal Main Harmonic Constants}

The sea tide phenomenon is essentially a superposition of its constituent components, these components are called tidal harmonic constants. In this case there are 9 main tidal harmonic constants listed in the Dishidros TNI AL tide list book, namely M2, S2, N2, K2, K1, O1, P1, M4, and MS4, but only 4 main components that influence the determination of the type or type of tide namely $\mathrm{M} 2, \mathrm{~S} 2, \mathrm{~K} 1$ and O1. Based on the 9 main tidal harmonic constants, an analysis called harmonic analysis can be carried out, namely the calculation of the amplitude and phase constants of several simple continuous harmonic movements which are considered to form a series of curve lines (Rawi, 1985).

The tide amplitude is the difference between the highest water level and the average water level or can be interpreted as half of the water ride. 
Whereas the tide phase is the time between two high water or two consecutive and not always the same low water shown in Figure 4. These constants are called Harmonic Components. These components are grouped into three parts, namely the Dual Daily, the single daily and the shallow waters.

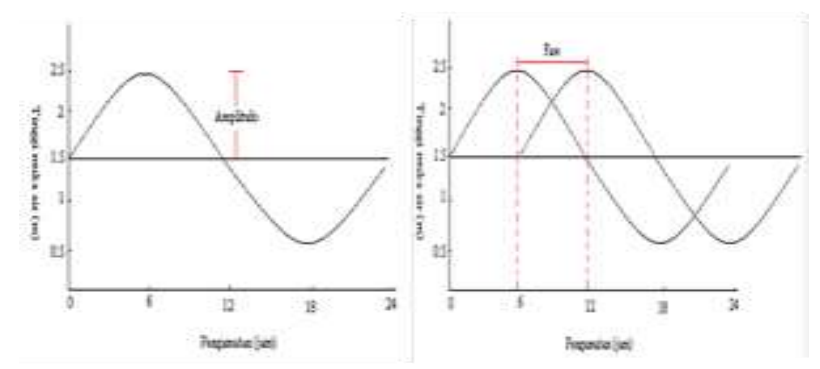

Fig.4 Amplitude and tide phase

\subsection{Definition of Lowest Astronomical Tide (LAT)}

Lowest Astronomical Tide is the lowest sea level position that occurs under average meteorological conditions and is the result of a combination of astronomical influences $(\mathrm{IHO}$, 2008). The definition of average meteorological conditions is related to meteorological influences on the position of the sea surface under normal conditions, not meteorological conditions that can cause the sea level to fall or rise in extreme ways. For example, such as during a storm flood, which can lead to a lower sea level position than LAT or during a tsunami that can cause a higher sea level position than the Highest Astronomical Tide (HAT) and can be lower than LAT.

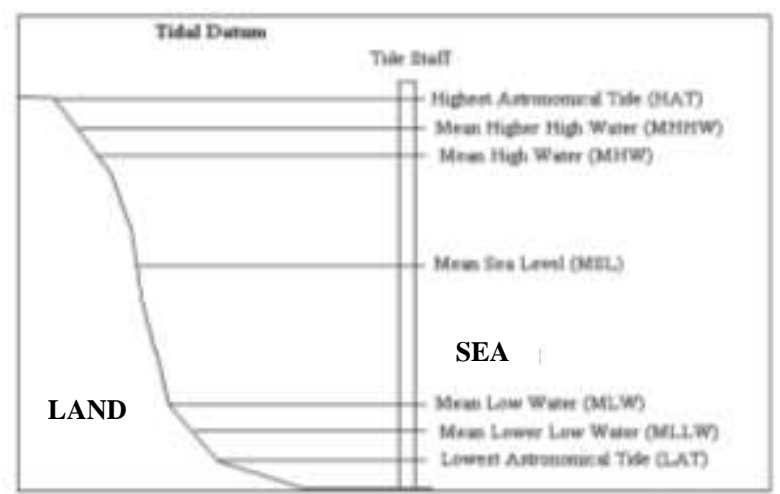

Fig.5 Tidal datum
Based on these definitions, LAT can be obtained by predicting the lowest sea level position using an 18.6-year time frame or based on tidal observation data over a period of 18.6 years. The prediction method is commonly used today because based on the results of a study of several tidal stations in the world that have tidal data records of more than 18.6 years, the use of tidal data directly is still very vulnerable to errors.

\subsection{LAT determination based on prediction results}

Good tide forecasting is needed for various navigation, hydrographic and marine and coastal building planning needs. In addition, the lowest astronomical tide determination is also based on tide forecasting. Therefore, to predict precisely the height of the tide in a particular place, accurate information is needed about the various tidal constants in that location. The tidal constant itself is obtained from a tidal analysis of sea level observation data over a period of time. The position of $h(t)$ or tide height when $t$ can be stated as follows (Rawi, 1985):

$$
h(t)=S o+\sum \quad f_{i} A_{i} \cos \left\{\left(V_{o}+u\right) i+\sigma_{i} t-g_{i}\right\}
$$

where:

$$
\begin{aligned}
& h(t) \quad=\text { tide height at } \mathrm{t} . \\
& \mathrm{t} \quad=\text { time in hours starting at } 00.00 \text { the } \\
& \text { beginning of the prediction time. }
\end{aligned}
$$

So $=$ the location of the tide face from Middle Sitting (Mean Sea Level) (obtained from data analysis)

$$
\begin{aligned}
& f_{\mathrm{i}} \quad=\text { node faktor } \\
& \left(V_{\circ}+u\right)=\text { argument ekuilibrium } \\
& \sigma \quad=\text { phase increment } \\
& \mathrm{A}, \mathrm{g} \quad=\text { Amplitudo and fase (harmonic } \\
& \text { constant) from field data analysis } \\
& \mathrm{i} \quad=\text { indeks / constanta }
\end{aligned}
$$


The lowest astronomical tide prediction process for 18.6 years, first determine the magnitude of the values $s, h, p$ and $N$ using the following table 2 .

Table 2. Value Determination of $s, h, p$ and $N$

\begin{tabular}{|c|c|c|}
\hline No. & Descrip. & \multicolumn{1}{|c|}{ Equation } \\
\hline 1 & $\mathrm{~s}$ & $277,025+129,38481(\mathrm{Y}-1900)+13,17640(\mathrm{D}+l)$ \\
\hline 2 & $\mathrm{~h}$ & $280,190-0,23872(\mathrm{Y}-1900)+0,98565(\mathrm{D}+l)$ \\
\hline 3 & $\mathrm{p}$ & $334,385+40,66249(\mathrm{Y}-1900)+0,11140(\mathrm{D}+l)$ \\
\hline 4 & $\mathrm{~N}$ & $259,157-19,32818(\mathrm{Y}-1900)-0,05295(\mathrm{D}+l)$ \\
\hline
\end{tabular}

Where:

$Y=$ prediction year to be made

$D=$ the number of days that passed from January 100.00 to 00.00 the date the prediction will be made

$\mathrm{I}=$ integral part of the year $=1 / 4(\mathrm{Y}-1901)$

Based on the prediction formula, the tidal data used for analysis purposes is tidal data that is free from systematic errors and major errors. The MSL component should be determined during the observation period of 18.6 years, while the tidal component involves a number of components representing the semi-diurnal, diurnal, shallow, and long period components so that the lowest sea level position is a combination of various influences astronomical.

These astronomical influences are represented by harmonic constants of tidal components involved in the prediction model, the results of the tidal analysis with input tidal data within a certain time period. In general, the longer the tide data used for analysis, the more tidal components produced. In this study, the determination of the LAT value was not based on observational data. Determination of LAT value is done by predicting using a harmonic approach, we need two tidal parameters resulting from tidal analysis using the least squares harmonic method approach.

\subsection{Determination of Tidal Harmonic Components}

The process of determining tidal harmonic components is carried out through two stages, namely tidal harmonic analysis, and tidal harmonic component selection. The tidal harmonic analysis is intended to obtain the magnitude (in centimeters) and the magnitude of the phase (in degrees) of each tidal harmonic constant. The selection of tidal harmonic components is intended to select the tidal harmonic components to be used in the determination of the lowest astronomical retrograde based on the Rayleigh Provisions.

The tidal harmonic analysis process is carried out using Matlab software that is run with the T-Tide program. The working principle of T-Tide software is based on the Least Squares method which is a method of harmonic analysis that describes tidal waves into several tidal harmonic components where the sea level height caused by tidal waves is the sum of the components of tidal generating force.

The tidal harmonic analysis process begins by first changing the tidal data units from meters to centimeters, then tidal data are grouped based on the order of observation time each hour using Microsoft Office Excel software. Then the process is continued by entering tidal data that has been grouped into T-Tide software so that the amplitude (in centimeters) and phase (in degrees) and Mean Sea Level (MSL) are obtained for each period of time observed.

\subsection{Rayleigh Criteria}

The position of the sea level in response to tidal phenomena is formed from astronomical and non-astronomical influences. If it is assumed that non-astronomical factors do not affect the tide phenomenon, then the position of the sea level can be expressed as a superposition of the astronomical component, and if described has the 
form as shown (5.a) which is a function of wave height with time, known as the time domain.

Then, if it is stated in the frequency domain it will be seen the component that forms it which is a function of the component signal strength (spectra) on the frequency of the component (figure 6).

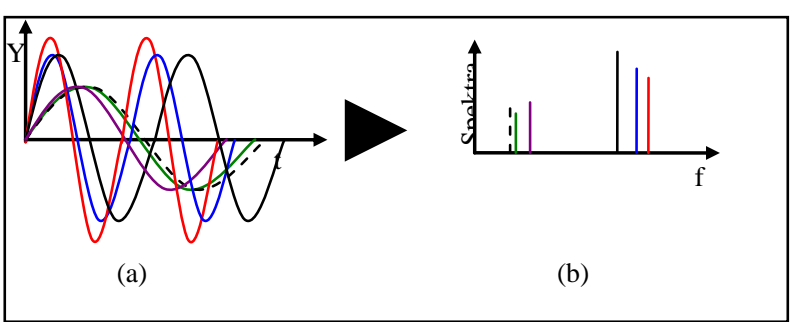

Fig.6 Representation of a signal

To obtain the tidal component, it is necessary to observe the position of the sea level with a certain interval and length of observation. In the tidal harmonic analysis, specifically using the least squares method, it will involve a number of components that have a certain frequency.

There are hundreds of tidal components with different species, which are generally classified as diurnal, semi-diurnal, long-period, and shallowwater species. In this study, the interval of observation data is one hour, while the data length varies from one month to one year. After the above criteria are applied, a number of tidal components will be selected, as can be seen in the Table below.

In other words, the component entered must have an important contribution to the tidal generation force, and the length of the observation must be sufficient to be able to separate the component from the comparative component. The size of the contribution of a tidal component is reflected in the value of the potential tidal amplitude it has.

\subsection{Calculate the Method Square Method Parameters}

In full count, several parameters are calculated, using alignment parameters, switching settings, combination settings, stepwise parameter settings, stepwise adjustment, and gradual combination leveling. The calculation method that will be discussed here is the parameter leveling method used for tidal analysis. The mathematical model that can be used to express the relationship between observations and parameters in calculating setting parameters is what states the parameter checking function. (Djunarsjah, 2004)

$$
(L+V)=f .(\hat{X})
$$

Where:

$$
\begin{array}{ll}
\mathrm{L}= & \text { vector of observations } \\
\mathrm{V}= & \text { correction vector } \\
\hat{X} & =\quad \text { parameter vector }
\end{array}
$$

The observational data will always be plagued by various errors, both systematic, random, and blunder. The least squares method can only be used for data that contains only random errors (meaning systematic errors and blunders no longer exist). Furthermore, to eliminate errors in observations that are random in nature, the mathematical model will always be accompanied by a correction vector $V$. If the above equation is written in the form of a matrix, then the equation becomes:

$$
A \hat{X}=\hat{L} \quad(n>u) ;
$$

Where:

$$
\begin{aligned}
& n=\text { the number of observations } \mathrm{L} \\
& u=\text { the number of parameters } \mathrm{X}
\end{aligned}
$$

Then the above equation can be written as follows:

$$
\begin{aligned}
& A\left(X^{o}+X\right)-(L+V)=0 \\
& L+V=A X^{o}+A X \\
& V=A X-\left(L-A X^{o}\right) \\
& V=A X-F
\end{aligned}
$$

Where:

$$
\begin{aligned}
& \mathrm{A}=\text { parameter coefficient matrix } \\
& \mathrm{V}=\text { correction vector } \\
& \mathrm{X}=\text { parameter vector } \\
& \mathrm{F}=\text { vector component }(\mathrm{L}-\mathrm{Xo})
\end{aligned}
$$


$\mathrm{Xo}_{\mathrm{O}}=$ magnitude of the parameter vector approach

\subsection{Research Flow}

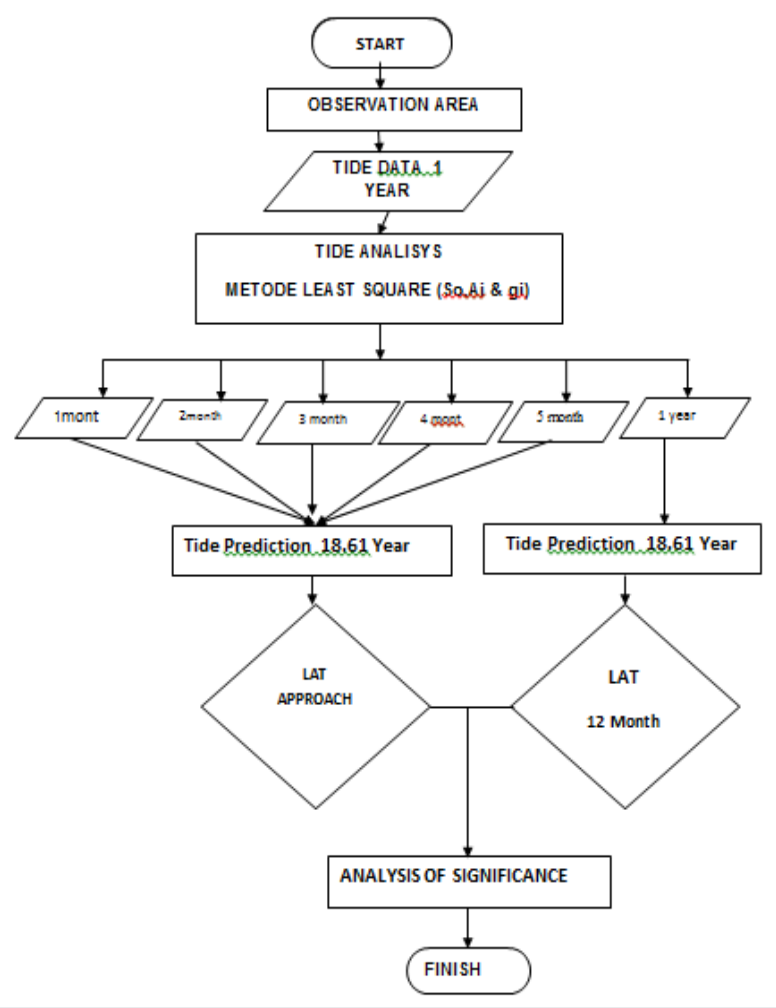

\subsection{Data Processing Method}

The method used in the preparation of this final assignment consists of several stages including through literature study, the stage of literature study is done by collecting various references such as books, scientific journals, articles, or through internet media. After going through the literature study stage, the data collection stage is carried out, then carrying out data processing using Matlab 7.0.1 software with the T-tide program. The data used in this Final Project is tidal data.

a. Research Sites. Observation data used were tide observation data by BIG on Benoa Waters for 1 year from January 1, 2000, to December 31, 2000. Observations using ATT Brand Type Graph tools Kempten with tide stations were at $08^{\circ} 46$ '00 "S and 115 ${ }^{\circ} 13^{\prime} 00$ "T which can be shown in figure 7 .

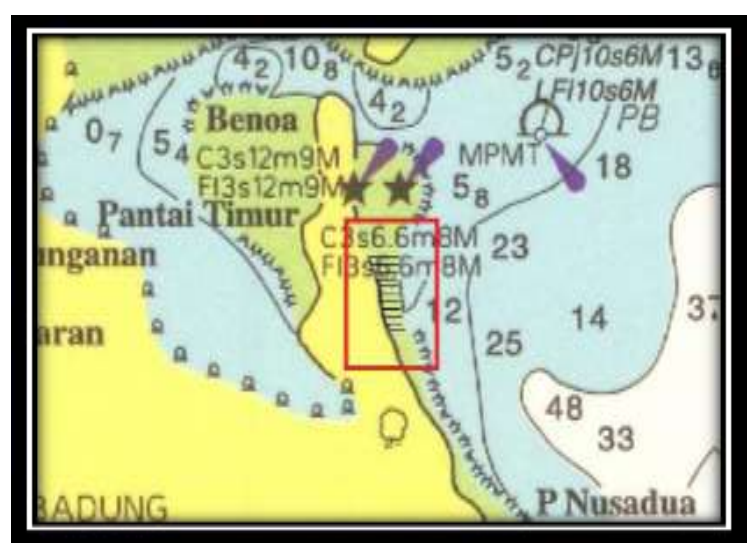

Fig.7 Research Sites

b. Defining Tidal Data. Before processing tidal data using MATLAB 7.0.1 software with the TTide program, first changing the shape of tidal data into tidal data in the form of a matrix according to the format needed by the T-Tide program. The composition of the tidal data matrix, namely, year, month, date, hour and perverted sea level as needed in the program. Furthermore, tidal data in the form of a matrix is ready to be processed and processed to obtain tidal analysis and predictive value of tide for 18.61 years.

The tidal harmonic analysis process begins by first changing the tidal data units from meters to centimeters, then tidal data are grouped based on the order of observation time each hour using Microsoft Office Excel software. Then the process is continued by entering tidal data that has been grouped into T-Tide software so that the amplitude (in centimeters) and phase (in degrees) and Mean Sea Level (MSL) are obtained for each period of time observed.

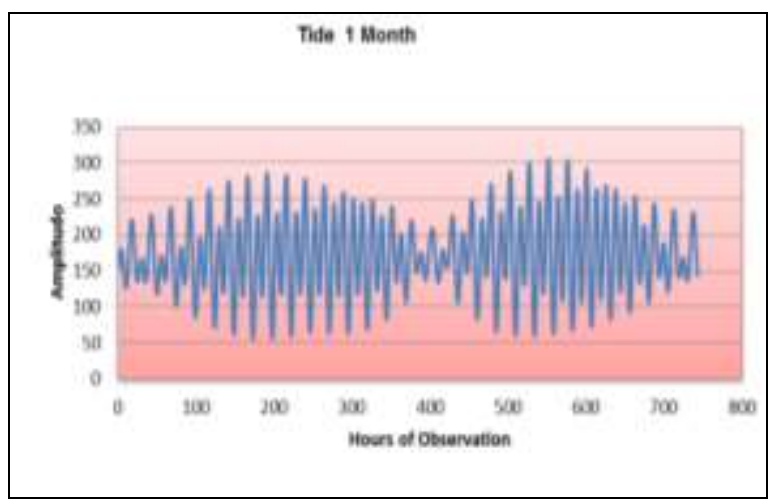

Fig.8 Tidal 1-month data graph 
c. Determination of the LAT Value. This value carried out in this study is based on the lowest ebb of the harmonic component superposition at intervals of 18.6 years ((14.6 years $\times 365$ days $\times 24$ hours $)+(4$ years $\times 366$ days $\times 24$ hours $)==$ 163032 hours. The amplitude analysis of each tidal harmonic component aims to determine that the minimum amplitude of each tidal harmonic component is at its lowest because the superposition of the minimum amplitude of each tidal harmonic component at the same time will produce the lowest low tide for the lowest astronomical ebb. This LAT Value determination uses Microsoft Exel assistance from the results of tidal forecasting for 18.61 years.

d. Determination of the level of significance of LAT values. Significance level analysis was obtained from the difference between the results of the position calculation of the LAT value of the 1year data with the results of the LAT value position with monthly data variations. The analysis was carried out by determining the level of difference in the LAT value of one-year data with the LAT value of each period of observation. From the results of the analysis, there will be several levels of differences that can later be classified as significant (S) or not significant (TS). For the purpose of analyzing the significance level of the results of this calculation, a statistical approach is used.

In statistics, the term "significance" is usually used to indicate a large deviation from the expected value of an event because of changes due to random sampling (Barry, 1978). An event is said to be significant if the deviation is greater than twice the standard deviation value of observation $(2 \sigma)$. To compare two or more average values from a series of measurements, we can use the standard deviation value $(\sigma R)$. The standard error of the difference between the two mean values $(\sigma \Delta)$ can be obtained from:

$$
\sigma_{\Delta}=\sqrt{\left(\sigma_{R}^{2}\right)_{A}+\left(\sigma_{R}^{2}\right)_{B}}
$$

If the difference in the two average values is greater than $2 \sigma \Delta$, the two values differ significantly. The equation will then be used to determine the significance level of the difference in the LAT value of one-year tide observation data with the position of the LAT value with a variety of observational data of less than one year.

\section{RESULT DAN DISCUSSION}

a. Monthly LAT Value data results

The results of the tide prediction calculation of the tidal constant superposition at an interval of 18.61 years to obtain a certain current water level $h$ (t) from the lowest water to the highest water indicate that each monthly variation data obtains the lowest diverse water level. This shows that the influence of tidal power styles changes at any time because of the rotation and evolution of the earth and moon against the sun.

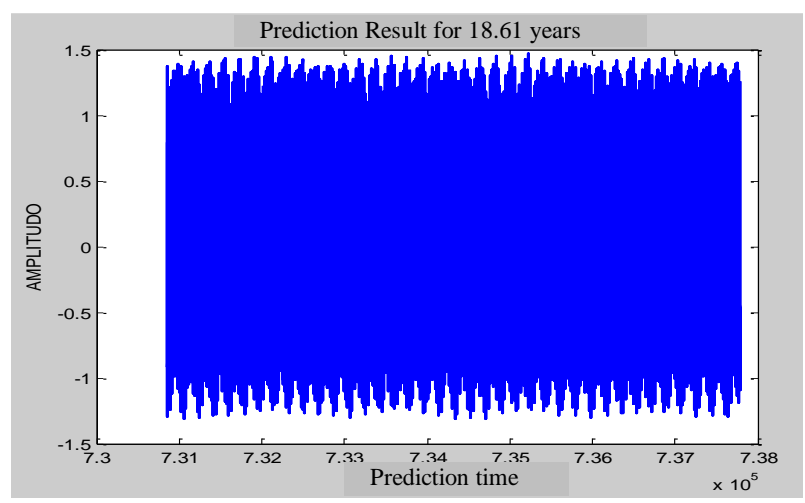

Fig.9 Tidal prediction results for 18.61 years

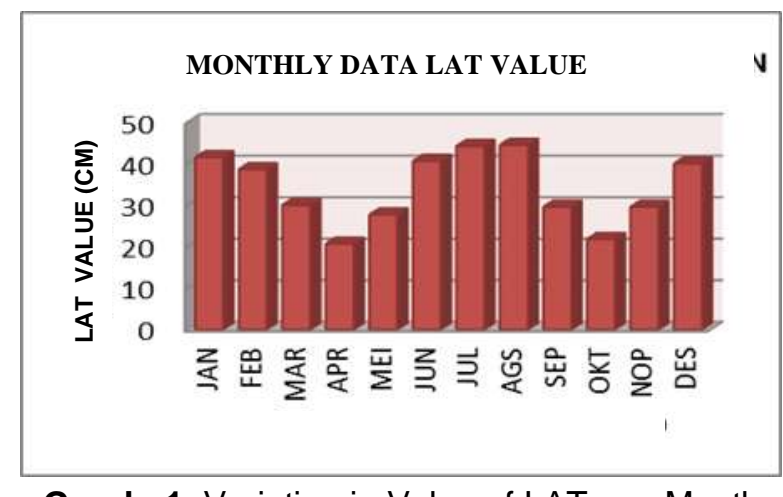

Graph 1 Variation in Value of LAT one Month 
Table 3. Variation in Value of LAT One monthly data

\begin{tabular}{|l|c|c|c|}
\hline \multirow{2}{*}{ MONTH } & LAT & MSL & Z0 \\
\cline { 2 - 4 } & $\mathbf{( c m )}$ & $\mathbf{( c m )}$ & $\mathbf{( c m )}$ \\
\hline January & 41.5 & 173 & 131.5 \\
\hline February & 38.6 & 174 & 135.4 \\
\hline March & 30.0 & 168 & 138.0 \\
\hline April & 20.7 & 161 & 140.3 \\
\hline May & 27.7 & 159 & 131.3 \\
\hline June & 40.6 & 165 & 124.4 \\
\hline July & 44.2 & 172 & 127.8 \\
\hline August & 44.5 & 174 & 129.5 \\
\hline September & 29.6 & 168 & 138.4 \\
\hline October & 21.8 & 161 & 139.2 \\
\hline November & 29.6 & 160 & 130.4 \\
\hline December & 40.0 & 165 & 125.0 \\
\hline
\end{tabular}

Table 4. Variation in Value of LAT Two monthly data

\begin{tabular}{|l|c|c|c|}
\hline \multirow{2}{*}{ MONTH } & LAT & MSL & Z0 \\
\cline { 2 - 4 } & $\mathbf{( c m )}$ & $\mathbf{( c m )}$ & $\mathbf{( c m )}$ \\
\hline January - Feb & 49.9 & 173.0 & 123.1 \\
\hline March - April & 27.5 & 165.0 & 137.5 \\
\hline May - June & 36.8 & 162.0 & 125.2 \\
\hline July - August & 45.6 & 173.0 & 127.4 \\
\hline Sept - October & 27.3 & 164.0 & 136.7 \\
\hline Nov - December & 33.8 & 162.0 & 128.2 \\
\hline
\end{tabular}

Table 5. Variation in Value of LAT Three monthly data

\begin{tabular}{|l|c|c|c|}
\hline \multirow{2}{*}{\multicolumn{1}{|c|}{ MONTH }} & LAT & MSL & Z0 \\
\cline { 2 - 4 } & (cm) & (cm) & (cm) \\
\hline January - March & 50.4 & 172.0 & 121.6 \\
\hline April - June & 34.7 & 162.0 & 127.3 \\
\hline July - September & 48.9 & 172.0 & 123.1 \\
\hline Oct - December & 32.5 & 162.0 & 129.5 \\
\hline
\end{tabular}

Table 6. Variation in Value of LAT Four monthly data

\begin{tabular}{|l|c|c|c|}
\hline \multicolumn{1}{|c|}{ MONTH } & LAT & MSL & Z0 \\
\cline { 2 - 4 } & $\mathbf{( c m )}$ & $\mathbf{( c m )}$ & $\mathbf{( c m )}$ \\
\hline January - April & 46.6 & 169.0 & 122.4 \\
\hline Mayu - August & 47.1 & 168.0 & 120.9 \\
\hline Sept - December & 33.8 & 163.0 & 129.2 \\
\hline
\end{tabular}

Tabel 7. Variation in Value of LAT Six monthly data

\begin{tabular}{|l|c|c|c|}
\hline \multirow{2}{*}{ MONTH } & LAT & MSL & Z0 \\
\cline { 2 - 4 } & $\mathbf{( c m )}$ & $\mathbf{( c m )}$ & $\mathbf{( c m )}$ \\
\hline January - June & 46.5 & 167.0 & 120.5 \\
\hline July - December & 48.5 & 167.0 & 118.5 \\
\hline
\end{tabular}

\section{b. Results of LAT Data for 1 Year}

From the results of tidal forecasting for 18.61 years using one-year observation data to obtain a
LAT value of $43.3 \mathrm{~cm}$. This one-year LAT value in this study is a LAT that is considered true. Then this LAT value will be compared with the LAT value with data of one month, two months, three months and four months and six months' data.

c. LAT Data One Year Value Difference with LAT Two-Month Data

Table 8. LAT Value Differences in One Year Data with 2000 Monthly Data

\begin{tabular}{|c|c|c|c|c|c|}
\hline MONTH & $\begin{array}{c}\text { LAT } \\
\text { MONTHLY } \\
(\mathrm{cm})\end{array}$ & $\begin{array}{c}\text { LAT } \\
\text { YEAR } \\
(\mathrm{cm})\end{array}$ & $\begin{array}{c}\Delta \text { LAT } \\
(\mathrm{cm})\end{array}$ & $\begin{array}{c}\text { STANDARD } \\
\text { DEVIATION } \\
(\mathbf{x} 2)\end{array}$ & $\begin{array}{c}\text { SIGNIFICATION } \\
\text { LEVEL }\end{array}$ \\
\hline JANUARY & 41.5 & 43.3 & 1.8 & 1.515 & $\mathrm{~S}$ \\
\hline FEBRUARY & 38.6 & 43.3 & 4.7 & 1.591 & $\mathrm{~S}$ \\
\hline MARCH & 30.0 & 43.3 & 13.3 & 1.572 & $\mathrm{~S}$ \\
\hline APRIL & 20.7 & 43.3 & 22.6 & 1.533 & $\mathrm{~S}$ \\
\hline MAY & 27.7 & 433 & 15.6 & 1.457 & $\mathrm{~S}$ \\
\hline JUNE & 40.6 & 43.3 & 2.7 & 1.456 & $\mathrm{~S}$ \\
\hline JULY & 44.2 & 43.3 & -0.9 & 1.516 & $\mathrm{TS}$ \\
\hline AUGUST & 44.5 & 43.3 & -1.2 & 1.582 & $\mathrm{TS}$ \\
\hline SEPTEMBER & 29.6 & 433 & 13.7 & 1.588 & $\mathrm{~S}$ \\
\hline OCTOBER & 21.8 & 43.3 & 21.5 & 1.544 & $\mathrm{~S}$ \\
\hline NOVEMBER & 29.6 & 43.3 & 13.7 & 1.464 & $\mathrm{~S}$ \\
\hline DECEMBER & 40.0 & 43.3 & 3.3 & 1.468 & $\mathrm{~S}$ \\
\hline
\end{tabular}

d. Level of Analision Significance Differences in LAT Value

From the results of tide forecasting with a one-month period observation data will be obtained a variance value $\left(\sigma^{2}\right)$, so that we can determine the standard deviation of each of the calculated data. The level of significance of the difference in LAT values can be seen in table 4.12. The difference in Non-Significant value (TS) occurs in the observation data in July and August while the other month the level of difference in LAT is significant (S).

Table 9. Significance Analysis of LAT Value for one-month data

\begin{tabular}{|c|c|c|c|}
\hline \multirow{2}{*}{ MONTH } & $\begin{array}{c}\text { LAT } \\
\text { MONTHLY }\end{array}$ & $\begin{array}{c}\text { LAT } \\
\text { YEAR }\end{array}$ & \multirow{2}{*}{$\begin{array}{c}\text { LAT } \\
(\mathbf{c m})\end{array}$} \\
\cline { 2 - 3 } & $\mathbf{( c m )}$ & $\mathbf{( c m )}$ & \\
\hline January & 41.5 & 43.3 & 1.8 \\
\hline February & 38.6 & 43.3 & 4.7 \\
\hline
\end{tabular}




\begin{tabular}{|c|c|c|c|}
\hline \multirow{2}{*}{ MONTH } & $\begin{array}{c}\text { LAT } \\
\text { MONTHLY }\end{array}$ & $\begin{array}{c}\text { LAT } \\
\text { 1 YEAR }\end{array}$ & $\begin{array}{c}\text { D LAT } \\
\text { (cm) }\end{array}$ \\
\cline { 2 - 3 } & $\mathbf{( c m )}$ & $\mathbf{( c m )}$ & \\
\hline March & 30.0 & 43.3 & 13.3 \\
\hline April & 20.7 & 43.3 & 22.6 \\
\hline May & 27.7 & 43.3 & 15.6 \\
\hline June & 40.6 & 43.3 & 2.7 \\
\hline July & 44.2 & 43.3 & -0.9 \\
\hline August & 44.5 & 43.3 & -1.2 \\
\hline September & 29.6 & 43.3 & 13.7 \\
\hline October & 21.8 & 43.3 & 21.5 \\
\hline November & 29.6 & 43.3 & 13.7 \\
\hline December & 40.0 & 43.3 & 3.3 \\
\hline
\end{tabular}

\section{CONCLUSION}

Based on the LAT calculation results from various lengths of observation, the lowest LAT position variation was $20.7 \mathrm{~cm}$ and the highest LAT position was $50.4 \mathrm{~cm}$

Variations in LAT values from various tide observation periods are as follows:

Table 10 Variations in LAT Values

\begin{tabular}{|c|c|c|}
\hline $\begin{array}{c}\text { OBSERVATION } \\
\text { TIME }\end{array}$ & $\begin{array}{c}\text { LOWEST LAT } \\
\text { (cm) }\end{array}$ & $\begin{array}{c}\text { HIGHEST LAT } \\
\text { (cm) }\end{array}$ \\
\hline 1 monthly & 20.7 & 44.5 \\
\hline 2 monthly & 27.3 & 49.9 \\
\hline 3 monthly & 32.5 & 50.4 \\
\hline 4 monthly & 33.8 & 47.1 \\
\hline 6 monthly & 46.5 & 48.5 \\
\hline 12 monthly & 43.3 & - \\
\hline
\end{tabular}

Variation and significance level of LAT values from various tide observation periods:

Table 11. Differences and levels of significance of LAT values

\begin{tabular}{|c|c|c|}
\hline $\begin{array}{c}\text { TIDE } \\
\text { OBSERVATION }\end{array}$ & $\begin{array}{c}\text { DIFFERENCE } \\
\text { LAT VALUE }\end{array}$ & LEVEL \\
\hline 1 month Vs 1 year & $(0.9-22.6)$ & $\mathrm{S}$ \\
\hline 2 month Vs 1 year & $(2.3-16.0)$ & $\mathrm{S}$ \\
\hline 3 month Vs 1 year & $(5.6-10.8)$ & $\mathrm{S}$ \\
\hline 4 month Vs 1 year & $(3.3-9.5)$ & $\mathrm{S}$ \\
\hline 6 month Vs 1 year & $(3.2-5.2)$ & $\mathrm{S}$ \\
\hline
\end{tabular}

The difference in the LAT value of one-year data with the LAT value of each period of observation, after analysis of the significance level with a statistical approach, obtained a significant level of difference, namely $0.9 \mathrm{~cm}$ to $22.6 \mathrm{~cm}$. This shows that the determination of LAT with data less than one year cannot be used for determining LAT values.

\section{ACKNOWLEDGMENT}

This research has been Supported by Indonesia Naval Technology College (STTAL), Indonesian Navy and Ministry of Defense of the Repulic Indonesia.

\section{REFERENCES}

Geospatial Information Agency. 2010. Indonesian National Standart, Hydrographic Survey Using Singlebeam Echosounder. Publisher Geospatial Information Agency. Jakarta.

Djunarsyah, Eka, 2004, Tidal Analysis of the Least Square Methide, ITB, Bandung.

Emery, 1991, Sea Level Land Level and Tide Gauges, Springer Verlag Gmbh.

Emery, 1998, Data Analysis Methods in Physical Oceanography, Second Edition, Elsevier.

Garrison, 2006, Essentials of Oceanography, Sixth Edition, USA.

Ingham, 1975, Sea Surveying, Department of Land Surveying, North East London Polytechnic.

International Hydrographic Office, 1993. A Manual on Technical Aspects of the United Nations Convention on the Law of the Sea - 1982, Special Publication No. 51 (Edisi III), International Hydrographic Bureau, Monaco.

International Hydrographic Office, (2008), Standards for Hydrographic Surveys, Special Publication No. 44, $5^{\text {th }}$ edition. Monaco.

Kurnia Malik. 2012. Long Observation Based Tidal Data Processing for Determination of Tidal Parameters and Chart datum (Case Study of Tarakan Waters).

Poerbandono dan Djunarsyah, E, (2005), Hydrographic Survey, Refika Aditama, Bandung.

Pugh, D. T. 1987. Tides, Surges and Mean Sea Level. John Wiles and Sons. 
Rawi, S., 1985, Tides, Diktat Lectures on Marine Engineering Education Survey, ITBBAKOSURTANAL.

Rawi, S., 2003, Tidal Teory, Indonesia Naval Technology College (STTAL), Jakarta.
UKHO. 2000, Significant Dissipation of Tidal Energy in the Deep Ocean Inferred from Satellite data, London. 